\title{
Effect of Energy Drinks on Rat Hippocampus and the Possible Neuroprotective Role of Sesame Oil: Histological, Immunohistochemical and Molecular Study
}

DOAA M. SHUAIB, M.D.

The Department of Anatomy \& Embryology, Faculty of Medicine, Cairo University

\begin{abstract}
Background: Energy drinks (EDs) consumption has increased dramatically over the past years and several adverse effects have been reported. Sesame oil (SO) is a potent antioxidant and anti-inflammatory dietary source for human health.

Aim of Study: The present study was assigned to investigate the possible neuroptotecive role of SO on energy drinksinduced hippocampal damage.

Material and Methods: Twenty adult male albino rats were divided into four groups; five rats in each (control, SO, EDs and EDs+SO). Routine histological examination was done, together with toluidine blue stain for dark neurons (DN) and glial fibrillary acidic protein (GFAP) immunostaining for astrocytes. Gene expression of catalase and tumor necrosis factor alpha (TNF-a) was analyzed using real-time polymerase chain reaction (PCR) and histomorphometric analysis was done.

Results: Histological examination of the hippocampus from EDs group showed shrunken pyramidal and granule cells, vacuolation and large pericellular spaces. There was significant decrease in neuronal thickness, increase in the number of DN and GFAP area percent compared to control group. Significant decrease in catalase gene expression was observed along with increase in TNF- a gene expression. Concomitant SO administration significantly improved the previously mentioned changes.

Conclusion: Energy drinks administration induced morphological and morphometric changes, deficient antioxidant capacity and inflammatory response in rat hippocampus. Sesame oil administration alleviated these adverse changes possibly due to its antioxidant and anti-inflammatory properties.
\end{abstract}

Key Words: Hippocampus - Energy drinks - Sesame oil Antioxidant-Anti-inflammatory.

\section{Introduction}

ENERGY drinks (EDs) are carbonated beverages that contain stimulating substances such as caffeine,

Correspondence to: Dr. Doaa Mahmoud Shuaib, E-Mail: doaa.shuaib@kasralainy.edu.eg taurine or guarana in combination with sugar, vitamin B12 and minerals [1]. The worldwide consumption of these drinks increased dramatically over the last decade because they have been marketed as a way to improve alertness and to reduce fatigue among adolescent and adults [2]. Negative health effects of short and long term consumption of EDs have been reported as aggressive behavior, low academic achievement, headache, irritation, tiredness and dissatisfaction to sleep [3]

Recent studies have suggested that consumption of EDs alone or combined with alcohol leads to oxidative stress and inflammatory response in the brain [4-6]. These processes are regulated by a reactive astrogliosis and an increase of proinflammatory cytokines, which trigger neuronal death [4]

The hippocampus is an important part of the brain that plays a role in spatial learning and memory [7]. It consists of two interlocking laminae of gray matter; the Cornu Ammonis and the dentate gyrus (DG). The Cornu Ammonis is divided into four regions; CA1, CA2, CA3 and CA4 [8]. It was reported that certain hippocampus regions (CA1, CA3 and DG) are especially sensitive to oxidative damage [9].

Natural antioxidants play a crucial role in reducing oxidative stress by removing the excess free radicals generated during oxidative metabolism [10] . Sesame oil (SO) is derived from the seeds of plant species of Sesamum indicum L. and belongs to family Pedaliaceae. It contains $83 \%-90 \%$ unsaturated fatty acids, $20 \%$ proteins, vitamins, minerals and large amount of lignans, such as sesamin, sesamol, sesamolin and tocopherols. It is characterized by its specific antioxidant, anti-inflammatory, antihypertensive as well as anticarcinogenic effect [11] 
In the reviewed literature, studies concerning the effect of EDs on the hippocampus were of limited number. Moreover, to our knowledge, the protective effect of SO on EDs-induced hippocampal damage was lacking. Therefore, the present study was assigned to demonstrate the effect of EDs on CA1, CA3 and DG regions of the hippocampus and the possible protective role of SO.

\section{Material and Methods}

The study was carried out in the Faculty of Medicine, Cairo University from March 2018 to February 2019.

\section{Animals:}

Twenty adult male albino rats of Sprague Dawley strain aged three to five months $(180-210 \mathrm{~g})$ were obtained from the Animal House, Faculty of Medicine, Cairo University. All experiments were performed in agreement with guidelines of the Cairo University of Medical Sciences for care and use of laboratory animals. For acclimatization, animals were handled daily and kept under observation for one week before to the beginning of the experiment. They were housed in plastic cages in suitable environment and regulated light with 12 hour light-dark cycles. All animals were fed on a constant adequate nutrition diet and allowed free access to drinking water ad libitum

\section{Energy drinks source and ingredients:}

Red Bull was purchased from local market in Cairo in the form of cans $(250 \mathrm{ml})$. Each $100 \mathrm{ml}$ contains water, sucrose, glucose, sodium citrate, citric acid, carbon dioxide, taurine $(0.4 \%)$, caffeine $(0.03 \%)$, inositol $(0.02 \%)$, niacin $(8 \mathrm{mg})$, pantothenic acid (2mg), vitamin B6 (2mg), B12 (0.002mg), riboflavin, caramel, natural and artificial flavoring and coloring agents.

\section{Sesame oil source:}

Cap Pharm sesame oil (Elcaptain Co., Egypt) was used in the present study. The oil was prepared from the best quality raw materials and the company's products have been registered at the Ministry of Health.

\section{Experimental design:}

The rats were divided into four groups (five rats in each) as follows:

\section{- Group I (Control group):}

The rats received $7.5 \mathrm{~mL}$ saline using a gastric tube daily for four weeks [12].

\section{- Group II (SO group):}

They were given SO by a gastric tube, at a dose of $4 \mathrm{~mL} / \mathrm{kg}$ daily for four weeks [13]

- Group III (EDs group):

They received EDs at a dose of $10 \mathrm{mg} / \mathrm{Kg}$ (equivalent to $7.5 \mathrm{~mL}$ ) daily for four weeks using a gastric tube [12].

- Group IV (EDs+SO group):

They received EDs at a dose of $10 \mathrm{mg} / \mathrm{Kg}$ and $\mathrm{SO}$ at a dose of $4 \mathrm{~mL} / \mathrm{kg}$ daily for four weeks using a gastric tube.

\section{Methods:}

At the end of experiment, the rats were euthanized by sudden cervical dislocation after light ether anesthesia six hours after the last meal. The skull was opened and the brain was rapidly excised. The cerebellum was removed and the cerebral hemispheres were separated into two halves by a median incision. The hippocampus was extracted from each cerebral hemisphere by a linear incision from the occipital pole to the frontal pole with the depth adjusted to cut only the cortex and corpus callosum and separate the central cortex area [14] The specimens were processed as follows:

\section{A- Histological study:}

The right hippocampi were fixed in $10 \%$ neutral buffered formalin ( $\mathrm{pH}$ 7.2), followed by dehydration, clearing and embedding in paraffin. Five $\mathrm{tm}$ thick paraffin sections were subjected to:

1-Hematoxylin and eosin $(H \& E)$ stain: For routine histological examination [15].

2- Toluidine blue stain: For detection of dark neurons (DN) (pre-apoptotic cells) [16] .

3- Glial fibrillary acidic protein (GFAP) immunostaining: For detection of astrocytes. Paraffin sections were dewaxed, rehydrated and incubated for 5 minutes with $3 \% \mathrm{H}_{2} \mathrm{O} 2$ in methanol to block endogenous peroxidase activity. Unmasking of antigenic sites was carried out by transmitting sections into $0.01 \mathrm{~mol} / \mathrm{l}$ citrate buffer (pH 6.0) for 10 minutes followed by boiling in a microwave for five minutes. Tissue sections were incubated with the primary antibody (antiGFAP, Goat Polyclonal IgG, anti-rat antibody; Dako Cytomation, Carpenteria, CA, USA, USA) for one hour with a 1: 1000 dilution. The sections were washed and incubated with biotinylated secondary antibodies and then with the avidin-biotin complex. Finally, sections were developed with $0.05 \%$ diaminobenzidine slides and counterstained with H\&E, dehydrated; 
cleared and mounted. Negative controls were performed by substituting the primary antibody with non-immune serum [15].

\section{B- Histomophometric study:}

Ten non overlapping high power fields ( $\mathrm{x} 400)$ from five sections (from each rat) of five rats per group were randomly chosen. The measurements were obtained using a Leica Qwin 500 (Cambridge, UK) computer assisted image analysis system.

\section{1- Pyramidal layer thickness in CA1 and CA3 regions:}

The thickness of pyramidal layer was measured (in H\&E stained sections. Lines were drawn perpendicular to the pyramidal-molecular layer junction, extending from the uppermost pyramidal cell to the lowermost detected one.

\section{2- Granular layer thickness in DG:}

The thickness of granular layer was measured (in $\mathrm{m}$. $\mathrm{H}$ E stained sections. Lines were drawn perpendicular to the junction between the granular cells and the hilus, extending from the uppermost granular cell to the lowermost detected one.

\section{3- The count of DN:}

Dark neurons were counted in CA1, CA 3 and DG in toluidine blue stained sections.

4- Area percent of positive GFAP immunoreaction were measured in CA1, CA3 and DG.

\section{C- Quantitative analysis of catalase and tumor} necrosis factor alpha (TNF- $\alpha)$ gene expression by real-time PCR:

\section{Total RNA extraction:}

Catalase is an antioxidant stress marker and TNF- $\alpha$ is an inflammatory marker. The left hippocampi were cut into small pieces and homogenized. Extraction of total RNA from tissue homogenate was done using SV Total RNA Isolation System (Promega, Madison, WI, USA) according to the instructions of the manufacturer. The purity and concentration of RNA were measured with an ultraviolet spectrophotometer.

\section{Complementary DNA (cDNA) synthesis:}

The cDNA was synthesized from 1 gRA using SuperScript ${ }^{\circledR}$ III First-Strand Synthesis System as described in the protocol of the manufacturer (\#K1621, Fermentas, Waltham, MA, USA). One otal RNA was mixed with 50 M digo (DT) $20,50 \mathrm{ng} / \mathrm{r}$ ndom primers and $10 \mathrm{mM}$ dNTP mix in a total volume of 10 The mixture was incubated at $56^{\circ} \mathrm{C}$ for 5 minutes and placed on ice for 3 minutes. The reverse transcriptase master mix containing 2 L $10 x$ RT buffer, 4 of $25 \mathrm{mM} \mathrm{MgCl} 2$, two $0.1 \mathrm{M}$ DTT and one L o SuperScript ${ }^{\circledR}$ III RT (200 U/ L) ras added to the mixture and was incubated at $25^{\circ} \mathrm{C}$ for 10 minutes followed by 50 minutes at $50^{\circ} \mathrm{C}$.

\section{Quantitative real-time PCR:}

Amplification and analysis of real-time PCR were performed using an Applied Biosystem instrument with software version 3.1 (StepOneTM, USA). The reaction contained SYBR Green Master Mix (Applied Biosystems), gene-specific primer pairs were designed with Gene Runner Software (Hasting Software, Inc., Hasting, NY) from RNA sequences from the gene bank. Quantitative realtime PCR was performed in a 25- Lremetion volume consisting of 2X SYBR Green PCR Master Mix (Applied Biosystems), 900nM of each primer and 2 LoDNA. Amplification conditions were: 2 minutes at $50^{\circ}, 10$ minutes at $95^{\circ}$ and 40 cycles of denaturation for 15 seconds and annealing/extension at $60^{\circ}$ for 10 minutes. Data from real-time assays were calculated using the $v 1.7$ sequence detection software from PE Biosystems (Foster City, CA). Relative expression of the studied genes was calculated using the comparative $\mathrm{Ct}$ method. All values were normalized to beta actin and reported as fold change (Table 1).

Table (1): The primers sequence for the studied genes.

\begin{tabular}{lcr}
\hline Isoform & Forward primer & Reversed primer \\
\hline Catalase & 5 '- GATGCTGTCT- & 5'- GATGCTGTCT- \\
& TCGTCATGC-3' & TCCGTCATGC-3' \\
TNF- $\alpha$ & 5 '- TGAGATTCGT- & 5'- GTCATGGCTTT- \\
& GCACAAGAGG & GGATGTCCT-3' \\
& 3' & \\
$\beta$-actin & 5 '- GGTCGGTGT- & 5'-ATGTAGGCCAT- \\
& GAACGGATTTGG & GAGGTCCACC-3' \\
& -3 ' & \\
\hline
\end{tabular}

TNF- $\alpha$ : Tumor necrosis factor alpha.

\section{Statistical analysis:}

Statistical analysis was performed using statistical package for the social sciences statistical software (SPSS) version 23.0 (IBM Corporation, Somers, NY, USA). The data was expressed as means \pm standard deviation (SD). Statistical data was compared using one-way analysis of variance (ANOVA). Any significant ANOVA was followed by post hoc Tukey test to detect which pairs of groups caused the significant difference. Significance was considered when the $p$-value was less than 0.05 . 


\section{Results}

A- Histological results:

Hematoxylin \& eosin stained sections:

Histological examination of H\&E stained sections of the control and SO groups showed similar results. The hippocampus was formed of Cornus Ammonis (CA1, CA2, CA3, CA4) and the DG (Fig. 1).

The CA1 and CA3 regions revealed three layers: Polymorphic, pyramidal and molecular. The CA1 region was composed of 4-5 layers of closely packed pyramidal cells, whereas CA3 showed few layers of loosely packed pyramidal cells. The pyramidal cells were formed of large vesicular nuclei with prominent nuclei and scanty triangular cytoplasm. Both the polymorphic and molecular layer contained few astrocytes (Fig. 2a,b).

The DG was formed of three layers: Outer molecular, intermediate granular and inner polymorphic layer. The granular layer was formed of dense columns of closely packed granule cells which appeared rounded or oval in shape with large vesicular nuclei, prominent nuclei and scanty cytoplasm. The molecular and polymorphic layers contained few astrocytes (Fig. 2c).

In EDs group, histological examination of CA1 and $\mathrm{CA} 3$ regions showed shrunken pyramidal cells with pyknotic nuclei and large pericellular spaces. Some cells showed flame like dark pointed tail, while others exhibited fargmentation and rarefaction of the cytoplasm. Ghost like appearance of pyramidal neurons was also observed. Numerous astrocytes and vacuolation were detected (Fig. $2 \mathrm{~d}, \mathrm{e})$. The DG showed shrunken granule cells with pyknotic nuclei surrounded by pericellular spaces. Ghost like granule cells and large clear areas were also detected. The molecular and poymorphic layers exhibited numerous astrocytes (Fig. 2f).

Examination of EDs+SO group showed improvement in the histoarchitecture of the hippocampus. Most of the pyramidal cells in CA1 and CA3 regions as well as granule cells of the DG had vesicular nuclei. There were few affected shrunken deeply stained cells with pyknotic nuclei and surrounded by pericellular spaces. Few vacuoles were encountred. Astrocytes were observed in the molecular and polymorphic layers (Fig. $2 \mathrm{~g}, \mathrm{~h}, \mathrm{i})$.

\section{Toluidine blue stained sections:}

Pyramidal cells in CA1, CA3 regions and the granules cells in the DG from the control group were stained light blue and had regularly shaped cell bodies (Fig. 3a,b,c). In EDs treated group, abundant DN with massive shrinkage and hyperbasophilia of the soma and nuclei were detected in the three regions of the hippocampus (Fig. 3d,e,f), whereas in EDs+SO group, few DN were observed in these regions (Fig. $3 \mathrm{~g}, \mathrm{~h}, \mathrm{i}$ ).

Glial fibrillary acidic protein immunostained
sections:
Glial fibrillary acidic protein immunostaining
showed few GFAP-positive astrocytes with few
processes in CA1, CA3 and DG regions of the
control group (Fig. $4 \mathrm{a}, \mathrm{b}, \mathrm{c}$ ). In EDs treated group,
numerous GFAP-positive astrocytes were found
in the three regions (Fig. $4 \mathrm{~d}, \mathrm{e}, \mathrm{f})$. Few GFAP-
reactive astrocytes were seen in these areas of
hippocampus in EDs+SO group (Fig. $4 \mathrm{~g}, \mathrm{~h}, \mathrm{i}$ ).

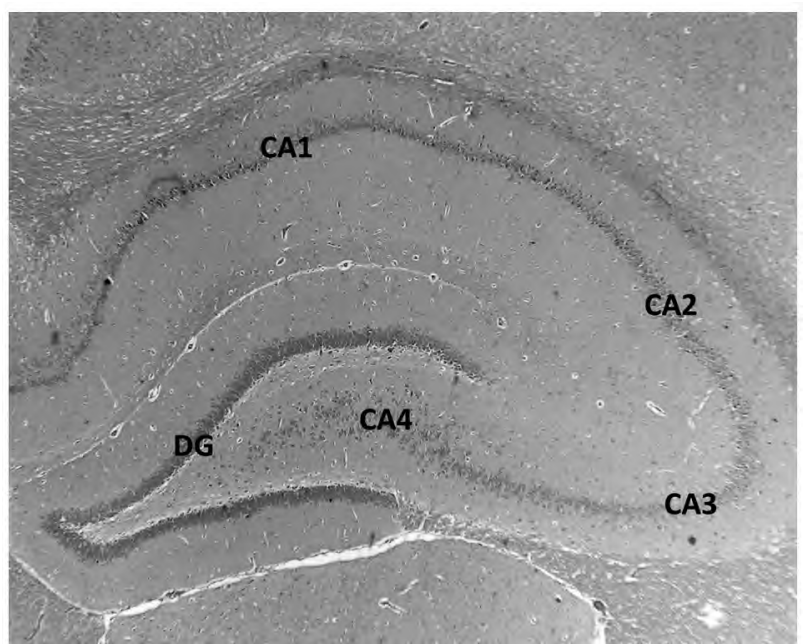

Fig. (1): A photomicrograph of hippocampus of adult male albino rat from control group showing the four areas of hippocampus proper (CA1, CA2, CA3 and CA4), as well as the dentate gyrus (DG). (H\&E x 40) 
CA1
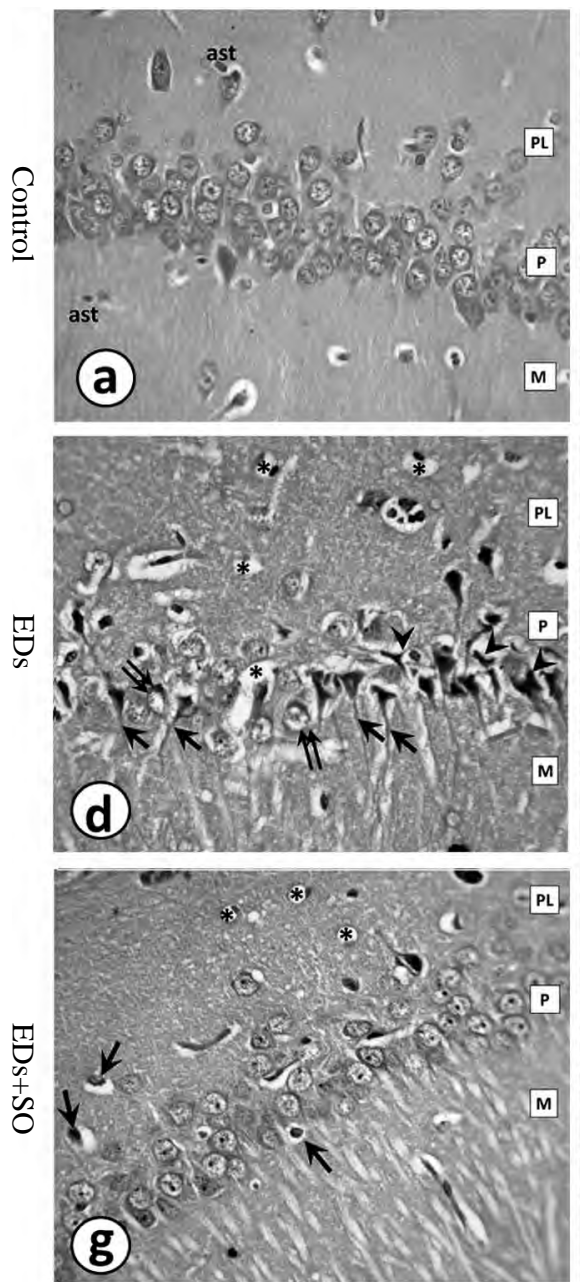

CA3
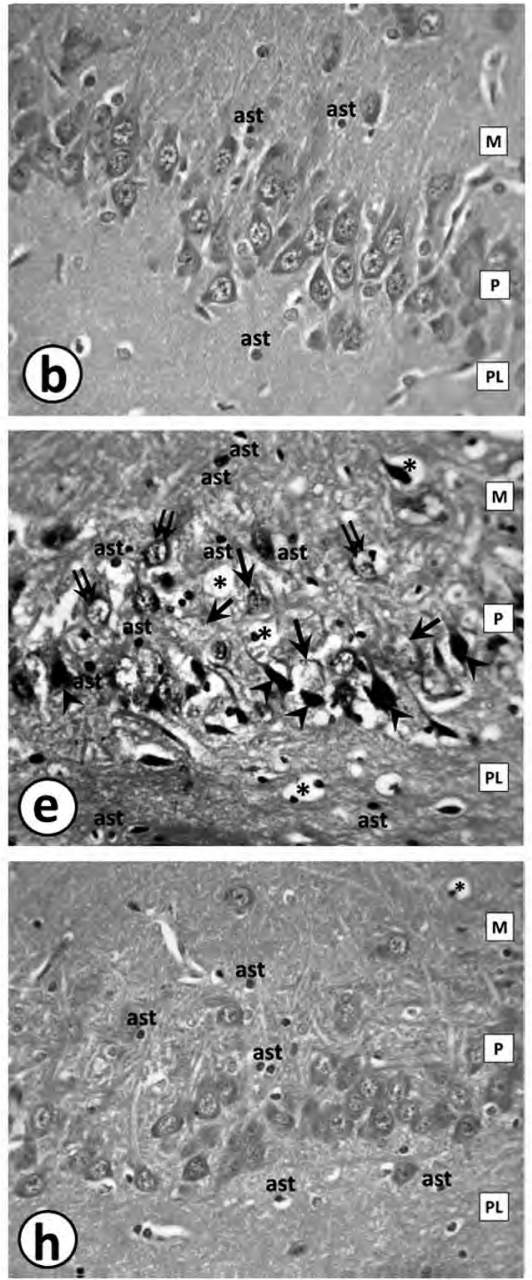

DG
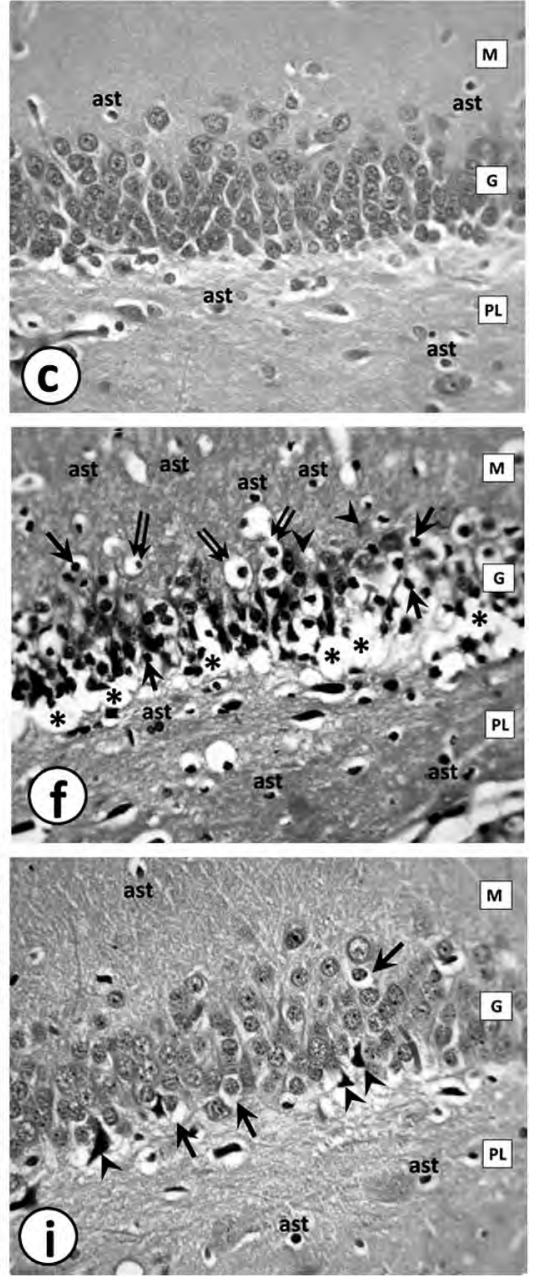

Fig. (2): Photomicrographs of sections of hippocampus of adult male albino rat:

$(\mathrm{a}, \mathrm{b})$ : The CA1 and CA3 regions of control group show closely packed pyramidal cells (P) in CA1 area and loosely packed cells in CA3 area. The polymorphic (PL) and molecular (M) layers show few astrocytes (ast).

(c): The dentate gyrus (D) of control group shows normal granule cells (G). The polymorphic (PL) and molecular (M) layers contain few astrocytes (ast).

(d): The CA1 region of EDs group shows shrunken pyramidal cells with wide pricellular spaces (arrow heads), rarefaction of the cytoplasm (double arrows), flame like dark pointed tail of some pyramidal cells (arrows) and vacuolation (asteriks).

(e): The CA3 region of EDs group shows shrunken pyramidal cells (arrow heads), fargmentation of the cytoplasm (double arrows), ghost like cells (arrows), vacuolation (asteriks) and numerous astrocytes (ast).

(f): The dentate gyrus of EDs group shows shrunken granule cells with pyknotic nuclei (arrows) surrounded by pericellualr spaces (double arrows), ghost like appearance (arrow heads), large clear areas (astericks) and numerous astrocytes (ast).

(g): The CA1 area of EDs+SO group shows appranetly normal pyramidal cells. Few cells are shrunken with pyknotic nuclei and surrounded by pericellular spaces (arrows). Few vacuoles (asteriks) are demonstrated.

(h): The CA3 area of EDs+SO group shows appranetly normal pyramidal cells. Numerous astrocytes (ast) are illustrated. Vacuole (asterik) is shown.

(i): The dentate gyrus of EDs+SO group show appranetly normal granule cells. Few cells are dark and shurnken (arrow heads). Some cells are surrounded by pericellualr spaces (arrows). Astrocytes (ast) are demonstrated. (H\&E x 400) 

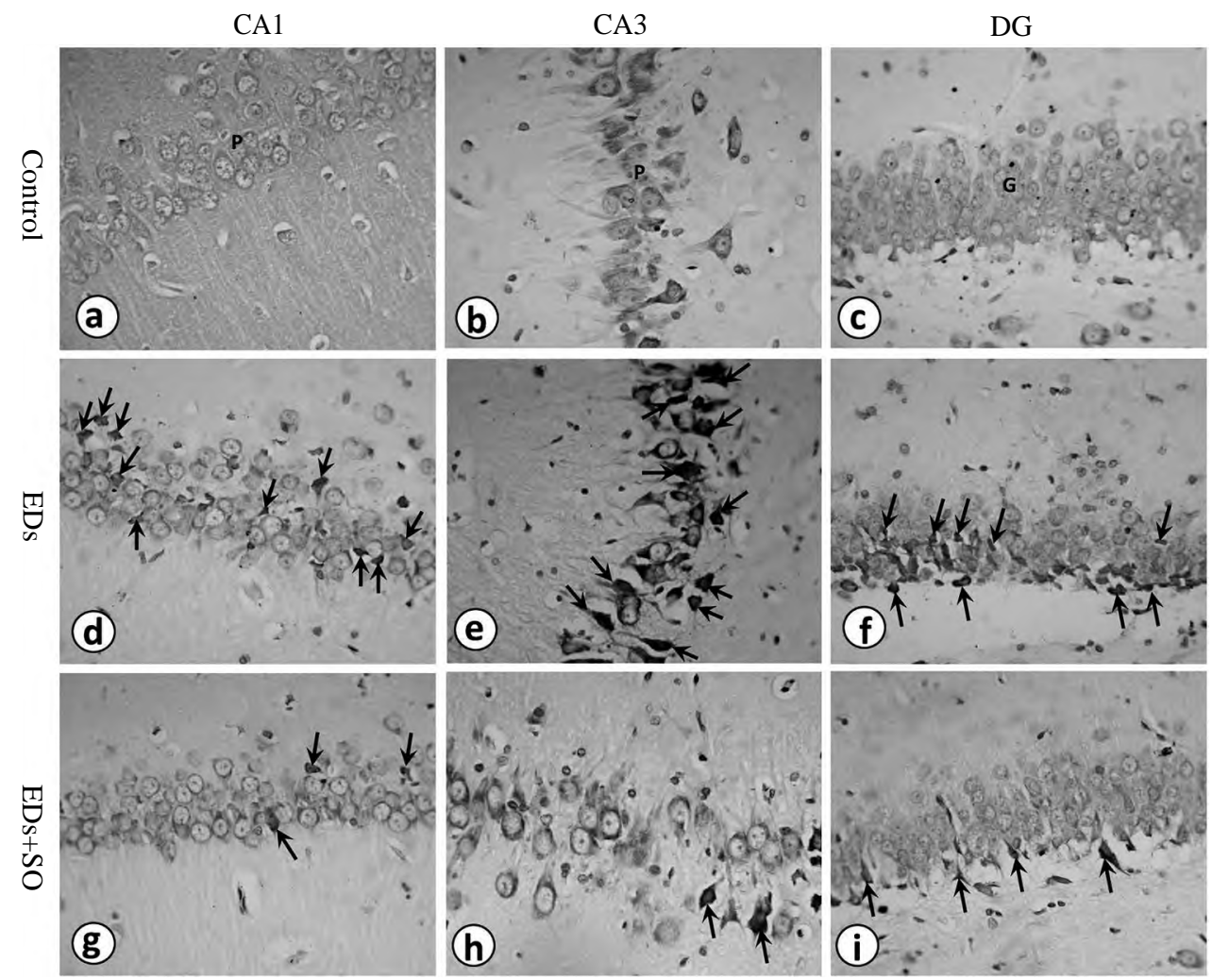

Fig. (3): Photomicrographs of sections of hippocampus of adult male albino rat showing light blue regular shaped pyramidal cells $(\mathrm{P})$ in CA1, CA3 of control group $(\mathrm{a}, \mathrm{b})$. Light blue granule cells $(\mathrm{G})$ are shown in DG of control group (c). Numerous DN (arrows) are illsutrated in CA1, CA3 and DG of EDs group (d, e, f). Few DN (arrows) are seen in EDs+SO group (g, h, i). (Toluidine blue x 400).
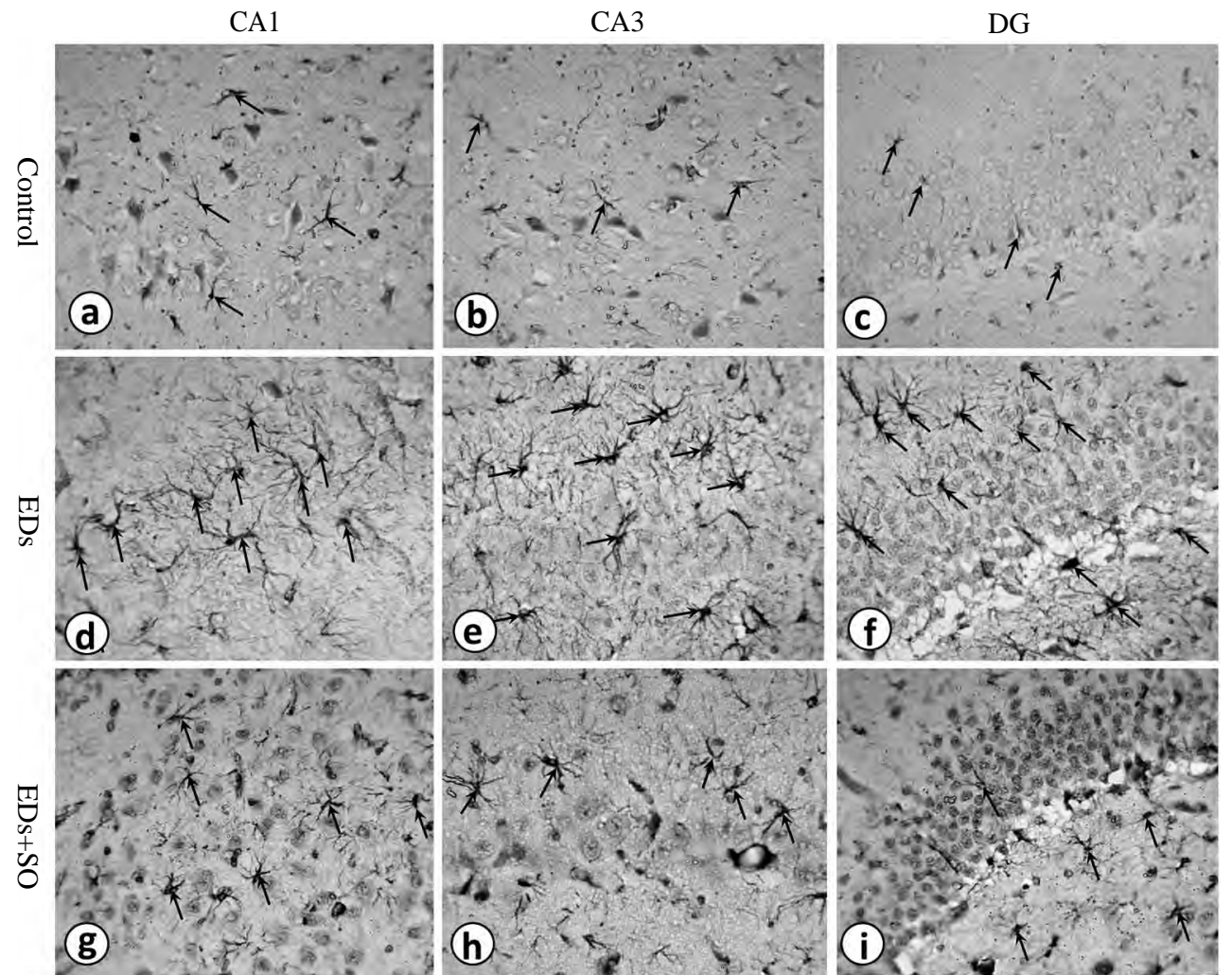

Fig. (4): Photomicrographs of sections of hippocampus of adult male albino rat showing few GFAP-positive astrocytes (arrows) in CA1, CA3 and DG of control group (a, b, c). Numerous GFAP-positive astrocytes (arrows) are shown in CA1, CA3 and DG of EDs group (d, e, f). The three regions show few GFAPpositive astrocytes (arrows) in EDs+ SO group (g,h,i). (GFAP x400). 


\section{B- Histomorphometric results:}

\section{1- Thickness of pyramidal and granular layers:}

Significant decrease in the mean thickness of pyramidal layer in CA1, CA3 and granular layer of DG was found in EDs group compared to control and $\mathrm{SO}$ groups. The EDs+SO group showed significant increase in the mean thickness of the pyramidal and granular layers compared to EDs group. In CA1 and DG, pyramidal thickness in EDs+SO group was significantly less than control and $\mathrm{SO}$ groups, while in CA3 region, the difference was non-significant (Table 2).

\section{2- Number of DN:}

Significant increase in the mean number of DN was found in CA1, CA3 and granular layer of DG in EDs group compared to control and SO groups. The EDs+SO group showed significant decrease in the mean number of DN compared to EDs group. In CA3 and DG, there was significant increase the mean number of DN in EDs+SO group compared to control and $\mathrm{SO}$ groups, while in CA1 region, the difference was non-significant (Table 3).

\section{3- The area percent of GFAP immunostaining:}

Significant increase in the mean GFAP area percent was found in CA1, CA 3 and granular layer of DG in EDs group compared to control and SO groups. The EDs+SO group showed significant decrease in the mean GFAP area percent compared to EDs group. In CA3 region, there was significant increase in the mean GFAP area percent in EDs+SO group compared to control and SO groups. In CA1 and DG, the difference was non-significant (Table 4).

\section{C- Gene expression of catalase and TNF- $\alpha$ in hippocampal tissue:}

There was significant decrease in catalase gene expression in the hippocampal tissue of rats in EDs group compared to control and SO groups. The $\mathrm{EDs}+\mathrm{SO}$ group showed significant increase in catalase gene expression compared to EDs group. Catalase gene expression in EDs+SO group was significantly decreased in comparison to control and SO groups (Table 5).

The gene expression of TNF- $\alpha$ in hippocampal tissue of EDs group showed significant increase compared to control and SO groups. The EDs+SO group showed significant decrease in TNF- $\alpha$ gene expression compared to EDs group. The gene expression of TNF- $\alpha$ was significantly increased in EDs+SO group compared to control and SO groups (Table 5).

Table (2): Mean thickness of pyramidal and granular layers in different groups.

\begin{tabular}{|c|c|c|c|c|c|c|c|c|c|}
\hline \multirow{2}{*}{ Group } & \multicolumn{3}{|c|}{ PTh-CA1 (m) } & \multicolumn{3}{|c|}{ PTh-CA3 ( } & \multicolumn{3}{|c|}{ GTh-DG ( } \\
\hline & Mean \pm SD & Versus & $p$-value & Mean \pm SD & Versus & $p$-value & Mean \pm SD & Versus & $p$-value \\
\hline Control & $86.3 \pm 10.05$ & & & $78.64 \pm 10.1$ & & & $71.29 \pm 9.21$ & & \\
\hline \multirow[t]{3}{*}{ SO } & $84.89 \pm 11$ & Control & 0.931 & $76.8 \pm 15.24$ & Control & 0.874 & $70.13 \pm 6.73$ & Control & 0.881 \\
\hline & & EDs & $0.000 *$ & & EDs & $0.000^{*}$ & & EDs & $0.000 *$ \\
\hline & & $\mathrm{EDs}+\mathrm{SO}$ & $0.034^{*}$ & & $\mathrm{EDs}+\mathrm{SO}$ & 0.379 & & $\mathrm{EDs}+\mathrm{SO}$ & $0.002 *$ \\
\hline \multirow[t]{3}{*}{ EDs } & $55.17 \pm 11.29$ & Control & $0.000 *$ & $49.27 \pm 8.76$ & Control & $0.000^{*}$ & $46.23 \pm 5.8$ & Control & $0.000 *$ \\
\hline & & SO & $0.000 *$ & & SO & $0.000 *$ & & SO & $0.000 *$ \\
\hline & & $\mathrm{EDs}+\mathrm{SO}$ & $0.000 *$ & & EDs+SO & $0.000 *$ & & $\mathrm{EDs}+\mathrm{SO}$ & $0.000^{*}$ \\
\hline \multirow[t]{3}{*}{$\mathrm{EDs}+\mathrm{SO}$} & $78.51 \pm 13.89$ & Control & $0.005^{*}$ & $72.89 \pm 13.57$ & Control & 0.089 & $64.37 \pm 9.25$ & Control & $0.000 *$ \\
\hline & & SO & $0.034 *$ & & SO & 0.379 & & SO & $0.002 *$ \\
\hline & & EDs & $0.000 *$ & & EDs & $0.000^{*}$ & & EDs & $0.000 *$ \\
\hline
\end{tabular}

*p-value significant.

PTh-CA1: Pyramidal layer thickness in CA1 region.

PTh-CA3: Pyramidal layer thickness in CA3 region.

GTh-DG : Granular layer thickness in DG; other abbreviations-see text. 
Table (3): The mean number of DN in different groups.

\begin{tabular}{llllllllll}
\hline \multirow{2}{*}{ Group } & \multicolumn{3}{c}{ DN-CA 1 } & \multicolumn{3}{c}{ DN-CA3 } & \multicolumn{3}{c}{ DN-DG } \\
\cline { 2 - 9 } & Mean \pm SD & Versus & $p$-value & Mean \pm SD & Versus & $p$-value & Mean \pm SD & Versus & $p$-value \\
\hline Control & $1.37 \pm 0.67$ & & & $2 \pm 0.41$ & & & $2.07 \pm 0.21$ & \\
SO & $1.53 \pm 0.22$ & Control & 0.991 & $2.23 \pm 0.33$ & Control & 0.974 & $1.93 \pm 0.16$ & Control & 0.997 \\
& & EDs & $0.000^{*}$ & & EDs & $0.000^{*}$ & & EDs & $0.000^{*}$ \\
& & EDs+SO & 0.472 & & EDs+SO & $0.003^{*}$ & & EDs+SO & $0.000^{*}$ \\
EDs & $18.37 \pm 3.78$ & Control & $0.000^{*}$ & $15.97 \pm 3.17$ & Control & $0.000^{*}$ & $17 \pm 3.16$ & Control & $0.000^{*}$ \\
& & SO & $0.000^{*}$ & & SO & $0.000^{*}$ & & SO & $0.000^{*}$ \\
& & EDs+SO & $0.000^{*}$ & & EDs+SO & $0.000^{*}$ & & EDs+SO & $0.000^{*}$ \\
EDs+SO & $2.37 \pm 0.13$ & Control & 0.309 & $4.17 \pm 1.07$ & Control & $0.001 *$ & $6.45 \pm 2.03$ & Control & $0.000^{*}$ \\
& & SO & 0.472 & & SO & $0.003^{*}$ & & SO & $0.000^{*}$ \\
& & EDs & $0.000^{*}$ & & EDs & $0.000^{*}$ & & EDs & $0.000^{*}$ \\
\hline
\end{tabular}

$* p$-value significant

DN-CA1: Number of dark neurons in CA1 region.

DN-CA3: Number of dark neurons in CA3 region.

DN-DG : Number of dark neurons in DG; other abbreviations-see text.

Table (4): The mean GFAP area percent in different groups.

\begin{tabular}{llllllllll}
\hline & \multicolumn{3}{c}{ GFAP\%-CA1 } & \multicolumn{3}{c}{ GFAP\%-CA3 } & \multicolumn{3}{c}{ GFAP\%-DG } \\
\cline { 2 - 10 } & Mean \pm SD & Versus & $p$-value & Mean \pm SD & Versus & $p$-value & Mean \pm SD & Versus & $p$-value \\
\hline Control & $2.27 \pm 0.69$ & & & $2.16 \pm 0.61$ & & & $2.03 \pm 0.57$ & \\
SO & $2.32 \pm 0.62$ & Control & 0.997 & $2.04 \pm 0.46$ & Control & 0.974 & $2.23 \pm 0.61$ & Control & 0.879 \\
& & EDs & $0.000^{*}$ & & EDs & $0.000^{*}$ & & EDs & $0.000^{*}$ \\
& & EDs+SO & 0.683 & & EDs+SO & $0.003^{*}$ & & EDs+SO & 0.305 \\
EDs & \multirow{2}{*}{$6.69 \pm 1.4$} & Control & $0.000^{*}$ & \multirow{2}{*}{$6.92 \pm 1.79$} & Control & $0.000^{*}$ & $6.83 \pm 1.78$ & Control & $0.000^{*}$ \\
& & SO & $0.000^{*}$ & & SO & $0.000^{*}$ & & SO & $0.000^{*}$ \\
& & EDs+SO & $0.000^{*}$ & & EDs+SO & $0.000^{*}$ & & EDs+SO & $0.000^{*}$ \\
EDs+SO & $2.58 \pm 0.62$ & Control & 0.553 & $3.1 \pm 0.87$ & Control & $0.010^{*}$ & $2.7 \pm 0.78$ & Control & 0.067 \\
& & SO & 0.683 & & SO & $0.003^{*}$ & & SO & 0.305 \\
& & EDs & $0.000^{*}$ & & EDs & $0.000^{*}$ & & EDs & $0.000^{*}$ \\
\hline
\end{tabular}

${ }^{*} p$-value significant.

GFAP\%-CA1: GFAP area percent in CA1 region.

GFAP\%-CA3: GFAP area percent in CA3 region.

GFAP\%-DG : GFAP area percent in DG; other abbreviations - see text.

Table (5): Gene expression of catalase and TNF- $\alpha$ in different groups.

\begin{tabular}{|c|c|c|c|c|c|c|}
\hline \multirow{2}{*}{ Group } & \multicolumn{3}{|c|}{ Catalase relative gene expression } & \multicolumn{3}{|c|}{ TNF- $\alpha$ relative gene expression } \\
\hline & Mean \pm SD & Versus & $p$-value & Mean \pm SD & Versus & $p$-value \\
\hline Control & $1.02 \pm 0.04$ & & & $1.00 \pm 0.02$ & & \\
\hline SO & $1.01 \pm 0.03$ & $\begin{array}{l}\text { Control } \\
\text { EDs } \\
\text { EDs+SO }\end{array}$ & $\begin{array}{l}0.985 \\
0.000 * \\
0.000^{*}\end{array}$ & $1.02 \pm 0.01$ & Control & $\begin{array}{l}0.997 \\
0.000^{*} \\
0.000^{*}\end{array}$ \\
\hline EDs & $0.19 \pm 0.03$ & $\begin{array}{l}\text { Control } \\
\text { SO } \\
\text { EDs+SO }\end{array}$ & $\begin{array}{l}0.000 * \\
0.000 * \\
0.000 *\end{array}$ & $4.58 \pm 0.31$ & EDs & $\begin{array}{l}0.000^{*} \\
0.000^{*} \\
0.000^{*}\end{array}$ \\
\hline $\mathrm{EDs}+\mathrm{SO}$ & $0.62 \pm 0.08$ & $\begin{array}{l}\text { Control } \\
\text { SO } \\
\text { EDs }\end{array}$ & $\begin{array}{l}0.000^{*} \\
0.000^{*} \\
0.000^{*}\end{array}$ & $2.02 \pm 0.07$ & $\mathrm{EDs}+\mathrm{SO}$ & $\begin{array}{l}0.000 * \\
0.000^{*} \\
0.000 *\end{array}$ \\
\hline
\end{tabular}

${ }^{*} p$-value significant; other abbreviations - see text. 


\section{Discussion}

The worldwide consumption of EDs has increased in recent years [6]. The present study investigated the harmful effect of EDs on rat hippocampus the possible ameliorative role of SO.

In the present study, examination of the hippocampi from EDs group revealed histopathological alterations in the form of shrunken neurons, pyknosis, cytoplasmic rarefaction, vacuolation. Significant decrease in the mean thickness of the pyramidal and granular layers was found in this group as compared to control and SO groups.

Significant increase in the number of DN in CA1, CA3 and DG was observed in EDs group as compared to the control and SO groups. Jekal and Cha [17] defined DN as pre-apoptotic cells which have undergone apoptotic changes but had not completed the process. On the other hand, Jortner [18] described them as neurons with dense cytoplasm and karyoplasm similar to necrotic cells. Gallyas et al., [19] reported that formation of DN is a type of cell death that is neither apoptosis nor necrosis. Dark neuron formation has been previously reported in brain trauma [18], ischemia, epilepsy, hypoglycemia [17] and silver toxicity [20]

Formation of DN in all these pathological conditions has been attributed to oxidative stress [20] It was reported that the depletion of antioxidant defense system causes damage of cellular components as lipids, proteins and DNA structures and even cell death [21]. The oxidative damage due to EDs consumption was confirmed in the current work by the significant decrease in catalase gene expression in hippocampal tissue of EDs group in comparison to the control and SO groups. Similar finding was observed by Mansy et al., [22], who reported a decrease in plasma catalase level in a study conducted on the liver and kidney of rats ingesting EDs.

With regard to GFAP immunoreaction, the present study revealed significant increase in GFAP area percent in CA1, CA3 and DG of the hippocampi of EDs group as compared to control and SO groups. These data were not consistent with Diaz et al., [4], who reported weak GFAP immunoreaction in the brain of rats treated with EDs alone and higher immunoreaction in the group treated with combined EDs and alcohol. This discrepancy might be due to the low dose of EDs used in their study $(7.5 \mathrm{~mL} / \mathrm{kg} /$ day $)$, although the duration of the experiment was longer (60 days). These data suggest that the harmful effect of EDs consumption depends on the dose rather than the duration.
Diaz et al., [4] reported that oxidative stress of the hippocampal neurons provokes inflammatory response and reactive astrogliosis. In the present work, this finding was confirmed by the significant increase in TNF-a gene expression in the hippocampal tissue of EDs group as compared to control and SO groups. This was in accordance with Ayuob and Beshbeishy [12], who reported significant increase of serum level of TNF- $a$ in rats ingesting EDs.

High concentration of caffeine has been suggested to be responsible for the main toxicity of EDs [5], however, the harmful effect of EDs on the nervous system could not be attributed to a single ingredient [6]. It was reported that combined caffeine, taurine and guarana consumption may induce cell death by reducing both superoxide dismutase and catalase activities in humans [23]. Moreover, sodium benzoate, as a preservative induces hippocampal damage and affects learning and memory [24].

In this study, the EDs+SO group showed improvement in the morphology of hippocampus as most of the pyramidal cells of CA1, CA3 and the granule cells of DG were apparently normal. Significant increase in the mean thickness of these layers was observed as compared to EDs group.

The mean number of DN in CA1, CA3 and DG in EDs+SO group decreased significantly as compared to EDs group. This improvement might be explained by the antioxidant effect of $\mathrm{SO}$, which was confirmed by the significant increase in catalase gene expression in $\mathrm{EDs}+\mathrm{SO}$ group in comparison to EDs group. Similarly, Saleem et al., [25] reported a significant increase in serum catalase level after SO administration to the rats with myocardial damage.

In EDs+SO group, the significant increase in the mean number of DN in DG compared to control and $\mathrm{SO}$ groups could be attributed to the oxidative stress load within the DG. It was reported that DG is a region of persistent lifelong neurogenesis, as it contains populations of quiescent neural stem cells. The process of neurogenesis is an energy intensive process that may be responsible for endogenous production of oxidative stress [26].

It was reported that astrocytes are important regulators of CNS inflammatory responses. When activated, they proliferate and release numerous cytokines including TNF-a [27]. In the present study, significant decrease in the mean GFAP area percent associated with decrease in TNF- a gene expression was found in the hippocampal tissue 
of EDs+SO group as compared to EDs group. These findings indicated decrease in the inflammatory response probably due to the anti-inflammatory properties of SO. Similarly, Cheng et al., [28] investigated the neuroprotective effect of sesamin and sesamolin; lignans in SO, in lipopolysaccharide-stimulated microglial cells. The authors reported that the excess generation of inflammatory mediators by microglia was inhibited by pretreatment of sesamin or sesamolin.

In the present study, there was partial improvement in the histology of hippocampal tissue of $\mathrm{EDs}+\mathrm{SO}$ group when compared to the control and SO groups. This was evidenced by the presence of few degenerated pyramidal and granule cells, the significant decrease in the pyramidal thickness, the increase in the number of DN and the increase in GFAP area percent in some regions of the hippocampus. These morphological and morphometric findings were confirmed by the significant decrease in catalase and increase in TNF- a gene expression in EDs+SO group compared to control and SO groups indicating residual oxidative damage and inflammatory response. This could be explained by the insufficient dose of $\mathrm{SO}(4 \mathrm{~mL} / \mathrm{kg})$ used in the current work. Similar findings were observed by Saleem et al., [25], who studied the protective effect of SO in two doses $(5 \mathrm{~mL} / \mathrm{kg}$ and $10 \mathrm{~mL} / \mathrm{kg})$ in rat model of myocardial injury. The authors reported that healthier protection of SO was observed with the dose of $10 \mathrm{~mL} / \mathrm{kg}$.

\section{Conclusion:}

In conclusion, EDs consumption developed morphologic and morphometric changes, oxidative damage and inflammation in rat hippocampus. Sesame oil offered significant protection via its antioxidant and anti-inflammatory properties.

\section{Compliance with ethical standards:}

Conflict of interest: The author declares no conflict of interest.

\section{References}

1- TAIWO O.I. and AYOADE A.: Toxicodynamic Effects of 'Red Bull' Energy Drink in A Randomised Controlled Study on Local Strains of Adult Rabbits. Journal of Biology and Life Science, 9 (1): 46-64, DOI: 10.5296/ jbls.v9i1.12651, 2018.

2- MARCZINSKI C.A.: Combined alcohol and energy drink use: Hedonistic motives, adenosine, and alcohol dependence. Alcohol. Clin. Exp. Res., 38 (7): 1822-5, doi: 10.1111/acer.12493, 2014.

3- HOLUBCIKOVA J., KOLARCIK P., MADARASOVA GECKOVA A., REIJNEVELD S.A. and VAN DIJK J.P.: Regular energy drink consumption is associated with the risk of health and behavioral problems in adolescents.
Eur. J. Pediatr., 176 (5): 599-605, doi: 10.1007/s00431017-2881-4, 2017.

4- DIAZ A., TREVINO S., GUEVARA J., MUNOZARENAS G., BRAMBILA E., ESPINOSA B., et al.: Energy Drink Administration in Combination with Alcohol Causes an Inflammatory Response and Oxidative Stress in the Hippocampus and Temporal Cortex of Rats. Oxid. Med. Cell. Longev., 8725354, doi: 10.1155/2016/8725354, 2016.

5- AL-SHAAR L., VERCAMMEN K., LU C., RICHARDSON S., TAMEZ M. and MATTEI J.: Health effects and Public Health Concerns of energy Drink Consumption in the United States: A Mini-Review. Front. Public Health, 5: 225, doi: 10.3389/fpubh.2017.00225, 2017.

6- AL-BASHER G.I., ALJABAL H., ALMEER R., ALLAM A.A. and MAHMOUD A.M.: Perinatal exposure to energy drink induces oxidative damage in the liver, kidney and brain, and behavioral alterations in mice offspring. Biomed Pharmacother., 102: 798-811, doi: 1016/j.biopha. 2018. 03.139, 2018.

7- LIU Y., GUAN W., REN G. and YANG Z.: The possible mechanism of silver nanoparticle impact on hippocampal synaptic plasticity and spatial cognition in rats. Toxicol. Lett., 209: 227-231, 2012.

8- EL FALOUGY H., KUBIKOVA E. and BENUSKA J.: The microscopical structure of the hippocampus in the rat. Bratisl Lek Listy, 109: 106-110, 2008.

9- CHANG B.J., JANG B.J., SON T.G., CHO I.H., QUAN F.S., CHOE N.H., et al.: Ascorbic acid ameliorates oxidative damage induced by maternal low-level lead exposure in the hippocampus of rat pups during gestation and lactation. Food Chem. Toxicol., 50: 104-108, 2012.

10-SHAFI S., ANSARI H.R., BAHITHAM W. and AOUABDI S.: The Impact of Natural Antioxidants on the Regenerative Potential of Vascular Cells. Front Cardiovasc. Med., 6: 28, doi: 10.3389/fcvm.2019.00028, 2019.

11- PATHAK K., RAHMAN S.W., BHAGAWATI S. and GOGOI B.: Sesame (Sesamum indicum L.), an underexploited oil seed crop: Current status, features and importance - A review. Agric. Rev., 38 (3): 223-227, 2017.

12- AYUOB N. and EL BESHBEISHY R.: Impact of an Energy Drink on the Structure of Stomach and Pancreas of Albino Rat: Can Omega-3 Provide a Protection? PLoS One, 11 (2): e0149191, doi:10.1371/journal.pone.0149191, 2016.

13- HSU D., CHU P. and JOU I.: Enteral sesame oil therapeutically relieves disease severity in rat experimental osteoarthritis. Food Nutr. Res., 60: 10.3402/fnr.v60.29807, 2016.

14- PALKOVITS M. and BROWNSTEIN M.J.: Microdissection of brain areas by the punch technique. In: Wiley J. Brain microdissection techniques. New York, Springer, pp. 1-36, 1983.

15- BANCROFT J.D. and GAMBLE M.: Theory and practice of histological techniques. 6 th edition, Churchill Livingstone Elsevier China, 2008.

16- KARIMOOY F.N., BIDESKAN A.E., POUR A.M. and HOSEINI S.M.: Neurotoxic Effects of Stanozolol on Male Rats' Hippocampi: Does Stanozolol cause apoptosis? 
Biomol Concepts, 10 (1): 73-81, doi: 10.1515/bmc-20190009, 2019.

17- JEKAL S.J. and CHA H.H.: Discrimination of early and late apoptotic cells by toluidine blue staining in paraffinembedded tissues. Korean. J. Clin. Lab. Sci., 30: 275290, 1998.

18- JORTNER B.S.: The return of the dark neuron. A histological artifact com-plicating contemporary neurotoxicologic evaluation. Neurotoxicology, 27 (4): 628-634, 2006.

19- GALLYAS F., KIGLICS V., BARACSKAY P., JUHSZ G. and CZURK A.: The mode of death of epilepsy-induced "dark" neurons is neither necrosis nor apoptosis: An electron-microscopic study. Brain Res., 1239: 207-215, 2008.

20- BAGHERI-ABASSI F., ALAVI H., MOHAMMADIPOUR A., MOTEJADED F. and EBRAHIMZADEHBIDESKAN A.: The effect of silver nanoparticles on apoptosis and dark neuron production in rat hippocampus. Iran. J. Basic. Med. Sci., 18 (7): 644-648, 2015.

21- BLOOMER R.J., TREPANOWSKI J.F. and FARNEY T.M.: Influence of acute coffee consumption on postprandial oxidative stress. Nutr. Metab Insights, 6: 35-42, 2013.

22- MANSY W., ALOGAIEL D.M., HANAFI M. and ZAKARIA E.: Effects of chronic consumption of energy drinks on liver and kidney of experimental rats. Trop. J. Pharm. Res., 16 (12): 2849-2856, 2017.

23- ZEIDAN-CHULIA F., GELAIN D.P., KOLLING E.A., RYBARCZYK-FILHO J.L., AMBROSI P., RESENDE
TERRA S., et al.: Major components of energy drinks (caffeine, taurine, and guarana) exert cytotoxic effects on human neuronal SH-SY5Y cells by decreasing reactive oxygen species production. Oxid. Med. Cell. Longev., Article ID791795, 2013.

24- KHOSHNOUD M.J., SIAVASHPOUR A., BAKHSHIZADEH M. and RASHEDINIA M.: Effects of sodium benzoate, a commonly used food preservative, on learning, memory, and oxidative stress in brain of mice. J. Biochem Mol. Toxicol., 32 (2), doi: 10.1002/jbt.22022, 2018.

25- SALEEM M.T., CHETTY M.C. and KAVIMANI S.: Putative antioxidant property of sesame oil in an oxidative stress model of myocardial injury. J. Cardiovasc. Dis. Res., 4 (3): 177-181, doi: 10.1016/j.jcdr.2013.07.001, 2013.

26- WALTON N.M., SHIN R., TAJINDA K., HEUSNER C.L., KOGAN J.H., MIYAKE S., et al.: Adult neurogenesis transiently generates oxidative stress. PLoS One, 7 (4): e35264, doi: 10.1371/journal.pone, 2012.

27- WEINBERG R.P., KOLEDOVA V.V., SCHNEIDER K., SAMBANDAN T., GRAYS ON A., ZEIDMAN G., et al.: Palm Fruit Bioactives modulate human astrocyte activity in vitro altering the cytokine secretome reducing levels of TNFa, RANTES and IP-10. Sci. Rep., 8 (1): 16423, doi: 10.1038/s41598-018-34763-3, 2018.

28- CHENG F.C., JINN T.R., HOU R.C. and TZEN J.T.: Neuroprotective effects of sesamin and sesamolin on gerbil brain in cerebral ischemia. Int. J. Biomed. Sci., 2 (3): 284-288, 2006.

\section{تأثير مشروبات الطاقة علي حصين الفأروالدور الوقائي المحتمل لزيت السمسيء:

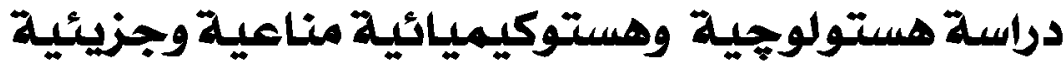

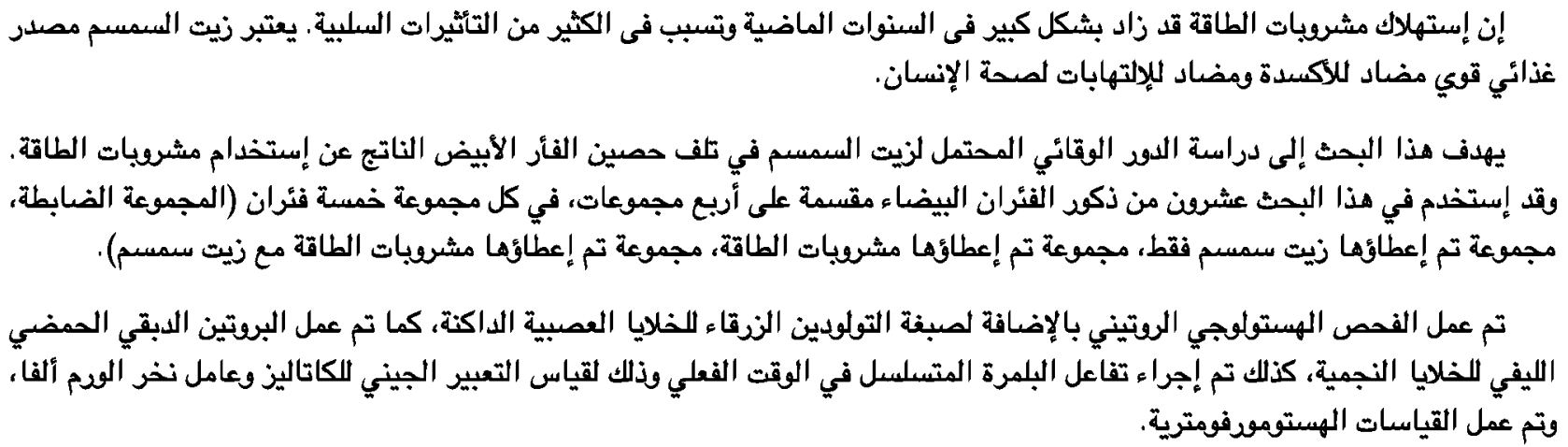

أظهر الفصص الهستولىجي وجود إنكماش في الخلايا الهرمية والصبيية، وقد وجد أن مشربات الطاقة قد تسبب في نقصان سمك الخلايا

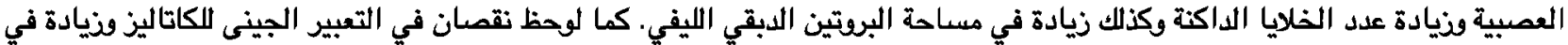
التعبير الجيني لعامل نخر المدم ألفاء وقد تبين أن إضافة زيت السمسم المصاحب لمشروبات الطاقة أدى إلى تحسن ملحوظ في كل التغيرات السابق ذكرها.

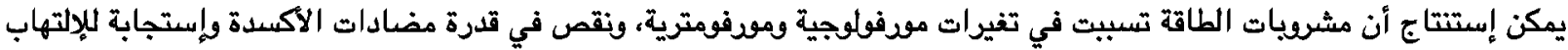

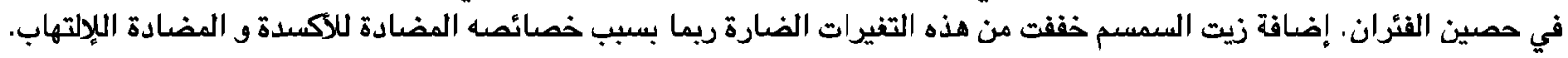

